\title{
Ammonia-oxidizing Archaea (AOA) are Winners to Survive in Oxygen-limited Habitat Compared to Ammonia-oxidizing Bacteria (AOB)
}

Peigang Dai ( $\nabla$ daipeigang@caas.cn )

Tobacco Research Institute of Shandong Province: Chinese Academy of Agricultural Sciences Institute of Tobacco Research https://orcid.org/0000-0001-5434-4018

\section{Wenjing Song}

Tobacco Research Institute of Shandong Province: Chinese Academy of Agricultural Sciences Institute of Tobacco Research

\section{Zhao Che}

Anhui Agricultural University

\section{Lili Zhang}

Anhui Agricultural University

\section{Zhaorong Dong}

Anhui Agricultural University

\section{Original Article}

Keywords: AOA, AOB, Niche specialization, Intertidal zone

Posted Date: February 17th, 2021

DOl: https://doi.org/10.21203/rs.3.rs-201180/v1

License: (c) (i) This work is licensed under a Creative Commons Attribution 4.0 International License. Read Full License 


\section{Abstract}

Purpose: Both ammonia oxidizing archaea (AOA) and bacteria (AOB) perform the ammonia oxidation together. These two kinds of microbes present a convenient model for studying niche specialization. To date, few surveys concentrated on the influence of oxygen concentration on niche specialization of AOA and $A O B$ in intertidal zones.

Methods: Here, high-throughput sequencing by Illumina MiSeq and qPCR were applied to detect the change of abundance, diversity as well as community structure of both $A O A$ and $A O B$ with $0-60 \mathrm{~cm}$ sediments depth in the intertidal zone in Qingdao.

Results and Conclusion: The AOA/AOB amoA gene copy numbers and AOA/AOB OTU numbers were all increased as sediment depth went deeper, which indicated that $A O A$ were more adaptive to oxygen-limited niches compared to $A O B$ and oxygen indeed led to the niche specialization of $A O A$ and $A O B$ in intertidal sediments. The dominant AOA and AOB were the Nitrosopumilus and Nitrosospira clusters, respectively, which indicated an ecological success in intertidal zone. Oxidation-reduction potential (ORP) was significantly positively correlated with AOB abundance and AOB OTU numbers $(P<0.01)$. In addition, both TN $(P<0.01)$ and $\mathrm{pH}(P<0.05)$ were significantly and negatively correlated with AOB abundance. TN was also significantly and negatively correlated with AOB OTU numbers $(P<0.05)$.

\section{Introduction}

Nitrification, a key role in the ecosystem nitrogen cycle, is the conversion of ammonia to nitrate through nitrite (Beeckman et al., 2018). Three kinds of microorganisms of ammonia oxidant, nitrite oxidizers and complete ammonia oxidizers were involved in the nitrification process (Stein and Klotz, 2016). Ammoniaoxidizing bacteria (AOB) was long thought to the only microorganism that performed ammonia oxidation, the first and rate-limiting step in nitrification. However, the ammonia oxidation theory was changed since the discovery of ammonia-oxidizing archaea (AOA) (Konneke et al., 2005). To date, several strains of AOA such as Candidatus Nitrososphaera gargensis (Hatzenpichler et al., 2008), Candidatus Nitrosocaldus yellowstonii (de la Torre et al., 2008), Candidatus Nitrosoarchaeum limnia SFB1 (Blainey et al., 2011) and Candidatus Nitrosotalea devanaterra (Laura et al., 2011), were enriched or isolated from various ecosystems. Until now, both $\mathrm{AOA}$ and $\mathrm{AOB}$ have been shown to perform ammonia-oxidizing (de la Torre et al., 2008; Hatzenpichler et al., 2008; Jia and Conrad, 2009). Various AOA and AOB functional gene abundance, community structures and activity patterns were reported in different biotopes (Wang, et al., 2020). Environmental factors play a key role in the niche differentiation between AOA and AOB. And the $A O A$ and $A O B$ relative contribution to ammonia oxidation in various ecosystems gradually become the hot spots in the field of ammonia oxidation.

As reported previously, a serious of environmental factors may cause the niche specialization between $\mathrm{AOA}$ and $\mathrm{AOB}$, such as $\mathrm{pH}$, temperature, salinity, ammonia concentrations and oxygen concentrations. AOA seems to be more adaptive in niches with lower $\mathrm{pH}$ and more likely to dominant the process of 
ammonia oxidation in acidic niches (Gubry-Rangin et al., 2011; Prosser and Nicol, 2012). AOB were more adaptable than $\mathrm{AOA}$ with increasing abundance but no alteration of composition at elevated temperature (Zhang et al., 2019b). Microcosm tests also verified that $\mathrm{pH}$ and temperature were key factors that leaded to the niche specialization of AOA and AOB (Aigle et al., 2020). Ammonia, as one of the substrate for ammonia oxidation, could cause niche specialization of $A O A$ and $A O B$. The concentration of ammonia half saturation constant of some AOB strains (Jung et al., 2011; Kim et al., 2012; Martens-Habbena et al., 2009) were much higher than AOA strains, indicated that AOA had higher affinity for ammonia than AOB. The half-saturation constants of Candidatus Nitrosoarchaeum koreensis MY1, Candidatus Nitrososphaera sp. JG1 and Nitrosopumilus maritimus SCM1 were $0.69 \mu \mathrm{M}, 2.15 \mu \mathrm{M}$ and $133 \mathrm{nM}$, respectively, which were much lower than that of Nitrosomonas europaea $(\mathrm{Km}=553 \mathrm{uM})$ (MartensHabbena et al., 2009). Therefore, AOA is more competitive than AOB in oligotrophic environment (Beman et al. 2008; Verhamme et al. 2011). In the aspects of other substrate for ammonia oxidation, oxygen could also lead to niche specialization of $A O A$ and $A O B$. The half-saturation constants for oxygen of AOA, such as Candidatus Nitrosoarchaeum koreensis MY1, Candidatus Nitrososphaera sp. JG1 and Nitrosopumilus maritimus SCM1 were 10.38, 4.67 and $3.90 \mu \mathrm{M}$, separately (Kim et al. 2012; Jung et al. 2011; Martens-Habbena et al. 2009), which were much lower than that of Nitrosomonas oligotropha NL7 $(76.3 \mu \mathrm{M})$ and Nitrosomonas europaea C-31 (183.3 $\mu \mathrm{M})$ (Parket et al. 2010; Park and Noguera 2007). The affinities of $A O A$ for oxygen were much higher than that of $A O B$, which means that $A O A$ had competitive advantages over $A O B$ in the oxygen-limited environments. The AOA lived better in many oxygen-limited environments. AOA dominated the transcriptome and probably dominated the ammonia oxidation process in the OMZ (Stewart et al. 2012). The increased of AOA OTU number and abundance ratio (AOA: AOB) in flooded soil proved that AOA could better adapt to low oxygen condition (Liu et al., 2015).

The intertidal zone is an ecological crisscross zone with important environmental and ecological functions affected by marine and terrestrial ecosystems (Community structure and organization of tidepools.). Tidal daily rhythm so that sediment is submerged or exposed to air. The Shazikou wharf was built in 1976 and was one of the biggest wharf in Qingdao. Near the wharf, was the biggest fish market in Qingdao. The human activities and the decayed fish provided enough ammonia nitrogen for the ammonia-oxidizing microbes in the intertidal zones nearby. The ecological distribution, including the community structure and of abundance $A O A$ and $A O B$ in intertidal zones have been discussed previously (Hu et al., 2019). However, the relationship between oxygen concentration and niche specialization of $A O A$ and $A O B$ was not investigated. So, the main objectives of this research are: (1) to study the difference of abundances and community structure of $A O A$ and $A O B$ in different layers/depth of the sediments in the intertidal zones, (2) to explore which, $A O A$ or $A O B$, was the main driver performing ammonia oxidation in different layers/depth of the sediments in intertidal zones, (3) to evaluate how the oxygen concentration influence the niche specialization of $A O A$ and $A O B$ in intertidal zones.

\section{Materials And Methods}




\section{Description of sampling sites, collection and physicochemical properties analysis of sediment}

The samples of sediment were collected using soil cylindrical sampler from the intertidal zone near the Shazikou wharf in Qingdao, Shandong Province. Three sampling sites (biological triplicates) along the sandy beach were selected. For each site, different depth $(0-10,10-20,20-30,30-40,40-50$ and 50-

$60 \mathrm{~cm}$, namely $S_{0-10}, S_{10-20}, S_{20-30}, S_{30-40}, S_{40-50}, S_{50-60}$, respectively) were sampled and sediments in the same depth were mixed. Totally six sediment samples were obtained. Each sample was divided into two subsamples: one, stored at $4^{\circ} \mathrm{C}$, was used for the physicochemical properties analysis; another, frozen at $-80^{\circ} \mathrm{C}$, was applied to molecular analysis. The $\mathrm{pH}$ and oxidation-reduction potential (ORP) were both measured in situ. The moisture content, inorganic nitrogen contents (including total nitrogen (TN), total inorganic nitrogen ( $\mathrm{TIN})$, ammonium $\left(\mathrm{NH}_{4}{ }^{+} \mathrm{N}\right)$, nitrite $\left(\mathrm{NO}_{2}{ }^{-}-\mathrm{N}\right)$ and nitrate $\left.\left(\mathrm{NO}_{3}{ }^{-}-\mathrm{N}\right)\right)$ were measured as described previously (Liu et al., 2013).

\section{DNA extraction and quantitative PCR of amoA genes}

We followed the manufacturer's instructions of a Power Soil DNA kit (Mo Bio Laboratories, Carlsbad, California, USA) to extract the DNA using $0.25 \mathrm{~g}$ soil. The extracted DNA quality was assessed on $1 \%$ agarose gel using a nanometer droplet spectrophotometer (ND-1000; Isogen Life Science, Netherlands) to measure the concentration of DNA.

The copy numbers of $A O A / A O B$ amoA genes were determined by the two primer sets (amoA-1F/amoA2-R for $A O B$ amoA genes and CamoA-19f/CamoA-616r for AOA amoA genes). According to the previously described embodiment, the use of real-time iCycleriQ5 thermal cycler and detection system (CA Bio-Rad) for qPCR. (Hu et al., 2014).

\section{High-throughput sequencing and bioinformatic analysisfor the amoA genes}

The functional genes (amoA genes) of $\mathrm{AOB}$ and $\mathrm{AOA}$ were amplified using the two primer sets as mentioned above. The protocols used to amplify the two functional genes have been described previously (Shen et al., 2008; Pester et al., 2012). Illumina MiSeq sequencing, carried out by Personalbio (Shanghai, China) was applied to ensure the good coverage of each clone libraries. Bar code oligonucleotides were connected to the ends of two pairs of primers to distinguish amoA amplicons of different samples. For each sample, triplicate PCR products were obtained and mixed together. The PCR products length was determined by electrophoresis in a 1.5\% agarose gel. Bioinformatic analysis was performed with the Mothur software package (Schloss et al., 2009). After screening, trimming and chimeras checking procedures, the high-quality reads were left for further analysis. Both $A O A$ and $A O B$ amoA genes were grouped into OTUs using a $85 \%$ similarity as a cut off as previously recommended 
(Pester et al., 2012). The diversity indices of ACE, Chao, Shannon and Simpson for each OTU were calculated.

\section{Statistical analysis}

BLASTN search was used to examine the representative sequences for all the OTUs of AOA and AOB. Non-AOA and $A O B$ amoA gene sequences and OTU were deleted. Pearson correlation analysis at significance level of 0.05 was used to determine the correlation between the AOA/AOB diversities and abundances and environmental factors. The representative sequences of all the OTUs for both AOA and $A O B$ and were imported into MEGA6 to construct alignment files in combination with the sequences of known sequences of $\mathrm{AOA}$ and $\mathrm{AOB}$. Phylogenetic analysis of $\mathrm{AOA}$ and $\mathrm{AOB}$ were performed using MEGA6 software with the neighbor-joining and maximum parsimony methods (Shen et al., 2014).

\section{Results And Discussion}

\section{sediment samples physicochemical properties}

Determination of physical and chemical properties of sediment samples, including $\mathrm{pH}$, oxidationreduction potential (ORP), moisture content, ammonium content, nitrite content, nitrate content, total inorganic nitrogen and total nitrogen content (TN) are presented in Table 1. All of the sediments had acidic $\mathrm{pH}$ values (i.e., $5.45-6.56)$. The $\mathrm{pH}$ value of the upper layer sediment samples $\left(\mathrm{S}_{0-10}, \mathrm{~S}_{10-20}\right)$ were

relatively lower than the middle $\left(\mathrm{S}_{20-30}, \mathrm{~S}_{30-40}\right)$ and deep layer $\left(\mathrm{S}_{40-50}, \mathrm{~S}_{50-60}\right)$, which probably resulted from the higher nitrification rates in the upper layer sediments. The ORP of the upper layer sediments were much higher than the rest of the samples. For the moisture, the middle layer was the highest. The ammonium content of the six sediment samples ranged from 1.32 to $6.21 \mathrm{mg} / \mathrm{kg}$ and the peak was found in the sample of $S_{30-40}$. All the sediment samples had low nitrite content as expected. The nitrate content ranged from 4.99 to $16.89 \mathrm{mg} / \mathrm{kg}$, and the nitrate content in the deep layer were higher than that of the upper layer. As for the TN, the content ranged from 857.77 to $1604.05 \mathrm{mg} / \mathrm{kg}$, and the TN content increased as the depth went deeper. 
Table 1

The physiochemical properties of the sediment samples

\begin{tabular}{|lllllllll|}
\hline $\begin{array}{l}\text { Sample } \\
\text { names }\end{array}$ & $\mathrm{pH}$ & $\begin{array}{l}\mathrm{ORP} \\
(\mathrm{mV})\end{array}$ & $\begin{array}{l}\text { Moisture } \\
(\%)\end{array}$ & $\begin{array}{l}\mathrm{NH}_{4}{ }^{+}-\mathrm{N} \\
(\mathrm{mg} / \mathrm{kg})\end{array}$ & $\begin{array}{l}\mathrm{NO}_{2}{ }^{-}-\mathrm{N} \\
(\mathrm{mg} / \mathrm{kg})\end{array}$ & $\begin{array}{l}\mathrm{NO}_{3}{ }^{-}-\mathrm{N} \\
(\mathrm{mg} / \mathrm{kg})\end{array}$ & $\begin{array}{l}\mathrm{TIN} \\
(\mathbf{m g} / \mathbf{k g})\end{array}$ & $\begin{array}{l}\mathrm{TN} \\
(\mathrm{mg} / \mathrm{kg})\end{array}$ \\
\hline $\mathrm{S}_{0-10}$ & 5.45 & 149.07 & 25.12 & 1.32 & 0.18 & 10.75 & 12.25 & 857.77 \\
\hline $\mathrm{S}_{10-20}$ & 5.91 & 105.88 & 35.23 & 1.30 & 0.18 & 4.99 & 6.47 & 1243.61 \\
\hline $\mathrm{S}_{20-30}$ & 6.01 & 76.86 & 41.44 & 1.55 & 0.48 & 12.73 & 14.76 & 1279.37 \\
\hline $\mathrm{S}_{30-40}$ & 6.56 & 75.10 & 44.02 & 6.21 & 0.79 & 16.89 & 23.90 & 1521.07 \\
\hline $\mathrm{S}_{40-50}$ & 6.23 & 83.17 & 39.50 & 3.77 & 0.67 & 16.21 & 20.65 & 1269.46 \\
\hline $\mathrm{S}_{50-60}$ & 6.29 & 89.39 & 39.56 & 4.98 & 0.51 & 11.61 & 17.11 & 1604.05 \\
\hline
\end{tabular}

\section{Abundance of $\mathrm{AOA}$ and $\mathrm{AOB}$}

In this study, the functional genes (amoA gene) of $A O A$ and $A O B$ in six sediment samples were quantitatively analyzed. The number of $A O A$ amoA genes of these sediment samples ranged from $1.26 \times 10^{7}$ to $2.82 \times 10^{8}$ and the number of $A O B$ amoA genes of the sediment samples ranged from $3.33 \times 10^{5}$ to $3.22 \times 10^{8}$ (Table S1). The number of AOA and AOB amoA genes observed in this work was similar to previous study in the intertidal zones in Zhoushan, Zhejiang province (Hu et al., 2019). Hu found that the $A O A$ and $A O B$ amoA gene copy numbers in the intertidal zone were both ranging from $10^{7}$ to $10^{8}$. The AOB amoA gene copy numbers in this study was relatively lower since samples $\mathrm{S}_{40-50}$ and $S_{50-60}$ were collected in the deep layers of the sediments. In the intertidal zones in Zhoushan, only surface sediments were collected for analysis. The AOA amoA gene copy numbers in the upper layers $\left(S_{0-10}, S_{10}\right.$ 20) were much lower than that in the middle $\left(\mathrm{S}_{20-30}, \mathrm{~S}_{30-40}\right)$ and deep $\left(\mathrm{S}_{40-50}, \mathrm{~S}_{50-60}\right)$ layer (Fig. 1). On the contrary to $A O A$ amoA genes, the number of $A O B$ amoA genes in the upper layers $\left(S_{0-10}, S_{10-20}\right)$ were much higher than that in the middle $\left(\mathrm{S}_{20-30}, \mathrm{~S}_{30-40}\right)$ and deep $\left(\mathrm{S}_{40-50}, \mathrm{~S}_{50-60}\right)$ layer (Fig. 1$)$. The ratio of AOA/AOB amoA gene copy numbers ranged from 0.04 to 150.75 in the 6 sediment samples and the ratio increased dramatically from upper layers to deep layers. The ratios of AOA/AOB amoA genes in the 6 sediment samples were $0.04\left(\mathrm{~S}_{0-10}\right), 0.11\left(\mathrm{~S}_{10-20}\right), 8.20\left(\mathrm{~S}_{20-30}\right), 7.07\left(\mathrm{~S}_{30-40}\right), 86.77\left(\mathrm{~S}_{40-50}\right)$ and 150.75 $\left(\mathrm{S}_{50-60}\right)$, respectively (Table $\left.\mathrm{S} 1\right)$. The ratios of $\mathrm{AOA} / \mathrm{AOB}$ amoA genes increased as the sediments depth went deeper, which indicated that AOA may dominated the ammonia oxidation in the deep layer. This founding was in accordance with the previous work focusing on the ammonia-oxidizing microbes in soils (Leininger et al., 2006). Leininger reported that the ratios of AOA/AOB amoA genes increased from 55 to 842 with soil depth went deeper. This phenomenoncould be explained by the higher affinities of AOA for oxygen compared to AOB (Martens-Habbena et al. 2009; Junget al. 2011; Kim et al. 2012). In the upper layers $\left(S_{0-10}, S_{10-20}\right)$ where the oxygen was sufficient, $A O B$ won the competition with $A O A$ and may be the 
main driver of ammonia oxidation. However, in the middle $\left(\mathrm{S}_{20-30}, \mathrm{~S}_{30-40}\right)$ and deep layer $\left(\mathrm{S}_{40-50}, \mathrm{~S}_{50-60}\right)$ where the environment became anoxic, the higher affinities of AOA for oxygen could help them to win the competition with $\mathrm{AOB}$. AOA outnumbered $\mathrm{AOB}$ in oxygen-limited environment was also previously mentionedin Zhoushan intertidal zones. In the middle tidal zone where the oxygen was relatively sufficient, the number of $A O B$ amoA genes was higher than that of $A O A$. In the subtidal zones where oxygen was limited, AOA outnumbered AOB (Hu et al., 2019). From the point of abundance, oxygen concentration indeed led to the niche specialization of $A O A$ and $A O B$.

\section{Diversity of $A O A$ and $A O B$}

High-quality $A O A$ and $A O B$ sequences after quality control procedures were applied to diversity analysis. Aa for AOA, a total of 17144 high-quality sequences were obtained for the 6 sediment samples. Using the $15 \%$ cut-off, which was recommended previously (Pester et al., 2012), a total of 18 OTUs were obtained for the amoA gene of archaeal. The coverages of the 6 AOA amoA gene clone libraries were all higher than $99.0 \%$, ranging from $99.80 \%$ to $99.96 \%$ (Table S2). The AOA OTU numbers of the 6 sediment samples ranged from 10 to 15 , with $S_{30-40}$ (10 OTUs) and $S_{50-60}$ (15 OTUs) displayed the lowest and highest diversity, respectively (Table S2). The OTU numbers in the deep layers were higher than that in the upper and middle layer (Fig. 2). Overall, the change rule of the AOA OTU numbers was similar to the AOA abundance, both of them increased with sediment depth. AOA showed higher diversity as oxygen concentration became lower, which was in accordance with previous work in water-level-fluctuating zones in Three Gorges Reservoir (Liu et al., 2015). At higher oxygen concentration of non-flooded areas, AOA OTU were lower value; In the relatively low oxygen concentration in flooded areas, AOA OTU values higher. This indicated that AOA was more adaptive to the oxygen-limited environments. A total of 18865 highquality AOA sequences were obtained form 6 sediment samples. Using 15\% as cutoff value (Purkhold et al., 2000), 18865 sequences were assigned to 11 OTUs. The coverages of the 6 AOB amoA gene clone libraries were ranging from $99.96 \%$ to $100.00 \%$ (Table S3). The sample $\mathrm{S}_{0-10}$ showed the highest diversity, holding 11 OTUs in total, which was higher than the rest 5 sediment samples (Fig. 2). The OTU numbers in the rest of the 5 samples were all the same, holding 8 OTUs (Table S3). Similar to the change rules of abundance, the AOB OTU numbers decreased as sediment depth went deeper, which indicated that AOB was not tolerant or adaptable to the hypoxic environments. The research in the area of water-levelfluctuating zones in Three Gorges Reservoir also showed the similar pattern. The AOB OTU numbers were always higher in the non-flooded zones where the oxygen concentration was sufficient than that in the flooded zones where the environment was anoxic. The diversity of $A O A$ was always higher than $A O B$ in all the sediment samples (Fig. 2) and the ratio of AOA/AOB OTU numbers increased from 1.09 to 1.88 as the sediment depth went deeper, which was similar to the change pattern of the abundance.

\section{Phylogenetic analysis and community structure of AOA and AOB}


After all the quality control procedures, for $\mathrm{AOA}$, totally 17144 high-quality sequences were obtained for the six sediment samples. According to the amoA genes classification of Archaea (Pester et al., 2012), the representative sequences of the 18 OTUs were grouped into four different clusters as shown in Fig. 3. Neither Nitrosotalea nor Thermal-related AOA was found in all the sediment samples. Nitrosophaera cluster contained 3 OTUs (OTU 12, OTU15, OTU 18), totally 9 sequences. OTU 12 (containing 3 seqs) belonging to Nitrosophaera cluster was retrieved from sample $S_{20-30}$ and $S_{40-50}$, OTU 15 (containing 2 seqs)was detected in sample $S_{0-10}$ and $S_{50-60}$, and OTU 18 (containing 4 seqs) was only retrieved from deep layer samples $\left(\mathrm{S}_{40-50}, \mathrm{~S}_{50-60}\right)$. The rest of the 15 OTUs were all affiliated with Nitrosopumilus cluster. Among the 17144 sequences, 17135 sequences were affiliated with Nitrosopumilus cluster, accounted for $99.94 \%$ of all the sequences obtained. Allthe six sediment samples were composed dominantly by sequences belonging to Nitrosopumilus cluster. The dominance of the Nitrosopumilus cluster over the Nitrosophaera clusterin this study was similar to previous studies in Chongming eastern intertidal sediments and in the intertidal zones in Zhoushan Island (Zheng et al., 2013; Hu et al., 2019). Phylogeny and meta-data analyses of archaeal amoA sequences also showed that the most of AOA belong to the Nitrosopumilus cluster (73\%), which was nearly twice as much as the Nitrososphaera cluster (37\%) (Alves et al., 2018). The failure of the Nitrososphaera cluster was more likely to form due to their inability to adapt to salty conditions or the fluctuation of intertidal environmental factors. AOB obtained 18865 sequences from 6 sediment samples by the same quality control procedure as AOA Using the $15 \%$ cut-off that was recommended in a previous study (Purkhold et al., 2000), 18865 sequences were assigned to 11 OTUs. The representative sequences of the 11 OTUs were grouped into two clusters, with 2 OTUs (OTU 9, OTU 10) clustered into the Nitrosomonas cluster and the remaining 9 OTUs clustered into the Nitrosospira cluster (Fig. 4). Only 35 sequences were affiliated with the Nitrosomonas cluster. All the six AOB communities were primarily composed of Nitrosospira-related sequences. The dominance of the Nitrosospira cluster over the Nitrosomonas cluster in this study was similar to previous studies in the coastal Pearl River estuary (Cao et al., 2011). The lower concentration of ammonia nitrogen (0.03 0.11 $\mathrm{mm} \mathrm{NH} 4+$ ) in the intertidal zone of Qingdao may help to explain the absolute dominance of nitrosoma and nitrosoma. The Nitrosomonas cluster has a lower affinity for the substrate and adapts to higher substrate concentrations. In contrast, the Nitrosospira cluster have relatively higher affinity with the substrate and are more likely to survive environments with low substrate concentrations (Zheng et al., 2014; Yu et al., 2016).

\section{Environmental factors that influence the diversity and communities of AOA and AOB}

Pearson correlation coefficient was used to analyze the linear relationship between different environmental factors and amoA gene abundance, OTU number, AOA, AOB diversity index, as shown in Table 2.. ORP was significantly positively correlated with AOB abundance and AOB OTU numbers $(P<$ $0.01)$, which mean that $A O B$ preferred the niches with higher oxygen concentrations. On the contrary, ORP was negatively correlated with AOA abundance, which mean that AOA preferred the niches with lower 
oxygen concentrations. All this could be explained by the higher affinity of AOA to oxygen compared to AOB. MC was significantly negatively correlated with AOB abundance $(P<0.01)$ and AOB OTU numbers $(P<0.05)$. TN was also found to be significantly negatively correlated with AOB abundance $(P<0.01)$ and AOB OTU numbers $(P<0.05)$. The $\mathrm{pH}$ value was negatively correlated with the abundance of AOB $(P$ $<0.05)$.

Table 2

Correlation analysis of environmental factors and $\mathrm{AOA}, \mathrm{AOB}$ abundance, OTU numbers and diversity index

\begin{tabular}{|c|c|c|c|c|c|}
\hline \multirow[t]{3}{*}{ Environmental factors } & \multicolumn{5}{|c|}{ Pearson correlation coefficient } \\
\hline & \multicolumn{2}{|c|}{ Relative abundance } & \multirow{2}{*}{$\begin{array}{l}\text { Ratio of abundance } \\
\text { AOA:AOB }\end{array}$} & \multicolumn{2}{|c|}{ Number of OTUs } \\
\hline & $\mathrm{AOA}$ & АOB & & $\mathrm{AOA}$ & AOB \\
\hline $\mathrm{pH}$ & 0.300 & -0.020 * & 0.423 & -0.919 & -0.055 \\
\hline ORP & -0.184 & $0.002^{* *}$ & -0.576 & 0.976 & $0.001 * \star$ \\
\hline MC & 0.250 & $-0.004 * *$ & 0.605 & -0.871 & $-0.014^{*}$ \\
\hline $\mathrm{NH}_{4}^{+}-\mathrm{N}$ & 0.503 & -0.178 & 0.320 & -0.887 & -0.392 \\
\hline $\mathrm{NO}_{2}^{-}-\mathrm{N}$ & 0.090 & -0.051 & 0.519 & -0.727 & -0.242 \\
\hline $\mathrm{NO}_{3}^{-}-\mathrm{N}$ & 0.083 & -0.273 & 0.676 & -0.600 & -0.755 \\
\hline TIN & 0.142 & -0.187 & 0.516 & -0.670 & -0.583 \\
\hline TN & 0.674 & $-0.029 *$ & 0.252 & 0.760 & $-0.045^{*}$ \\
\hline
\end{tabular}

\section{Conclusion}

In summary, our results showed the change pattern of the abundance and diversity of $A O A$ and $A O B$ with sediment depth. In the upper layers, the abundance of $A O B$ was higher than that of $A O A$, and in the deep layers, $A O A$ outnumbered $A O B$. Both the ratio of $A O A / A O B$ amoA gene copy numbers and AOA/AOB OTU numbers increased as sediment depth went deeper, which indicated that oxygen indeed led to the niche specialization of $A O A$ and $A O B$ and $A O A$ won the competition with $A O B$ in the oxygen-limited niches. $A O A$ may dominant the ammonia oxidation process in the deep layers. The Nitrosopumilus and Nitrosospira clusters were the absolute dominant $A O A a n d A O B$, respectively, indicating an ecological success in the intertidal zone.

\section{Declarations}




\section{Acknowledgements}

The authors gratefully acknowledge funding from Ministry of Education of the People's Republic of China and Department of Education, Anhui Province.

\section{Author's contributions}

All the authors collaborated for the completion of this work. DP designed and accomplished the first draft. SW, CZ and ZL were involved in the initial writing and editing of the manuscript. DZ provided valuable insights and suggestions for this article.

\section{Funding}

This study was supported by the National College Student Innovation and Entrepreneurship Training Program (202010364050) and Key Scientific Research Project in Colleges and Universities of Anhui Province (KJ2019A0177).

\section{Availability of data and materials}

Not applicable.

\section{Ethics approval and consent to participate}

Not applicable.

\section{Consent for publication}

All listed authors consented to the submission of this manuscript for publication.

\section{Competing interests}

The authors declare no competing interest.

\section{References}

1. Aigle A, Gubry-Rangin C, Thion C, Estera-Molina KY, Richmond H, Pett-Ridge J, et al., 2020. Experimental testing of hypotheses for temperatureandpH-based niche specialization of ammoniaoxidizing archaea and bacteria. Environmental Microbiology, 22 (9), 4032-4045. 
2. Alves RJE, Minh BQ, Urich T, von Haeseler A, Schleper C (2018) Unifying the global phylogeny and environmental distribution of ammonia-oxidising archaea based on amoA genes. Nat Commun $9(1): 1517$.

3. Baolan H, Shuai L, Wei W, Lidong S, Liping L, et al. 2014. pH-dominated niche segregation of ammonia-oxidising microorganisms in Chinese agricultural soils. FEMS microbiology ecology 90:290-9.

4. Beeckman, F., Motte, H., Beeckman, T., 2018. Nitrification in agricultural soils: impact,actors and mitigation. Current Opinion in Biotechnology 50, 166-173.

5. Beman JM, Popp BN, Francis CA (2008) Molecular and biogeochemical evidence for ammonia oxidation by marine Crenarchaeota in theGulf of California. ISME J 2:429-441.

6. Blainey PC, Mosier AC, Potanina A, Francis CA, Quake SR. 2011. Genome of a low-salinity ammoniaoxidizing archaeon determined by single-cell and metagenomic analysis. PloS one 6:e16626.

7. Cao HL, Hong YG, Li M, Gu JD (2011) Diversity and abundance of ammonia-oxidizing prokaryotes in sediments from the coastal Pearl River estuary to the South China Sea. Antonie Van Leeuwenhoek 100(4):545-556.

8. de la Torre JR, Walker CB, Ingalls AE, Konneke M, Stahl DA. 2008. Cultivation of a thermophilic ammonia oxidizing archaeon synthesizing crenarchaeol. Environmental microbiology 10:810-8.

9. Gubry-Rangin, C., Hai, B., Quince, C., Engel, M., Thomson, B.C., James, P., Schloter, M.,Prosser, J.I., Nicol, G.W., 2011. Niche specialization of terrestrial archaeal ammoniaoxidisers. Proceedings of the National Academy of Sciences 108, 21206-21211.

10. Hatzenpichler R, Lebedeva EV, Spieck E, Stoecker K, Richter A, et al. 2008. A moderately thermophilic ammonia-oxidizing crenarchaeote from a hot spring. Proceedings of the National Academy of Sciences of the United States of America 105:2134-9.

11. Hu JJ, Liu S, Yang WL, He ZF, Wang JQ, Liu Huan, et al., 2019. Ecological Success of the Nitrosopumilus and Nitrosospira Clustersin the Intertidal Zone. Microbial Ecology (2019) 78:555-564.

12. Jia, Z., Conrad, R., 2009. Bacteria rather than Archaea dominate microbial ammonia oxidation in an agricultural soil. Environ Microbiol 11: 1658-1671.

13. Jung MY, Park SJ, Min D, Kim JS, Rijpstra WI, Sinninghe Damste JS,Kim GJ, Madsen EL, Rhee SK (2011) Enrichment and characterizationof an autotrophic ammonia-oxidizing archaeon of mesophiliccrenarchaeal group I.1a from an agricultural soil. Appl EnvironMicrobiol 77:8635-8647.

14. Kim JG, Jung MY, Park SJ, Rijpstra WI, Sinninghe Damste JS, MadsenEL, Min D, Kim JS, Kim GJ, Rhee SK (2012) Cultivation of ahighly enriched ammonia-oxidizing archaeon of thaumarchaeotalgroup I.1b from an agricultural soil. Environ Microbiol 14:1528-1543.

15. Konneke M, Bernhard AE, de la Torre JR, Walker CB, Waterbury JB,Stahl DA (2005) Isolation of an autotrophic ammonia-oxidizingmarine archaeon. Nature 437:543-546.

16. Laura E. Lehtovirta-Morley KS, Andreas Vilcinskas, James I. Prosser,and Graeme W. Nicol. 2011. Cultivation of an obligate acidophilic ammonia oxidizer from a nitrifying acid soil. 
17. Leininger S, Urich T, Schloter M, Schwark L, Qi J, et al. (2006) Archaeapredominate among ammoniaoxidizing prokaryotes in soils. Nature 442: 806-809.

18. Liu S, Hu BL, He ZF, Zhang B, Tian GM, Zheng P, Fang F (2015) Ammonia-oxidizing archaea have better adaptability inoxygenated/hypoxic alternant conditions compared to ammoniaoxidizingbacteria. Appl Microbiol Biotechnol 99:8587-8596.

19. Liu S, Shen L, Lou L, Tian G, Zheng P, Hu B. 2013. Spatial distribution and factors shaping the niche segregation of ammonia-oxidizing microorganisms in the Qiantang River, China. Applied and environmental microbiology 79:4065-71.

20. Martens-Habbena W, Berube PM, Urakawa H, de la Torre JR, Stahl DA(2009) Ammonia oxidation kinetics determine niche separation ofnitrifying Archaea and Bacteria. Nature 461:976-979.

21. Park HD, Noguera DR (2007) Characterization of two ammoniaoxidizingbacteria isolated from reactors operated with low dissolvedoxygen concentrations. J Appl Microbiol 102:1401-1417.

22. Park BJ, Park SJ, Yoon DN, Schouten S, Sinninghe Damste JS, Rhee SK(2010) Cultivation of autotrophic ammonia-oxidizing archaea frommarine sediments in coculture with sulfur-oxidizing bacteria. ApplEnviron Microbiol 76:7575-7587.

23. Pester M, Rattei T, Flechl S, Grongroft A, Richter A, et al. 2012. amoA-based consensus phylogeny of ammonia-oxidizing archaea and deep sequencing of amoA genes from soils of four different geographic regions. Environmental microbiology 14:525-39.

24. Prosser, J.I., Nicol, G.W., 2012. Archaeal and bacterial ammonia oxidisers in soil: thequest for niche specialisation and differentiation. Trends in Microbiology 20,523-531.

25. Purkhold U, Pommerening-Roser A, Juretschko S, Schmid MC, KoopsHP, Wagner M (2000) Phylogeny of all recognized species of ammoniaoxidizers based on comparative 16S rRNA and amoA sequenceanalysis: implications for molecular diversity surveys.Appl Environ Microbiol 66:5368-5382.

26. Schloss PD, Westcott SL, Ryabin T, Hall JR, Hartmann M, et al. 2009. Introducing mothur: opensource, platform-independent, community-supported software for describing and comparing microbial communities. Applied and environmental microbiology 75:7537-41.

27. Shen JP, Zhang LM, Zhu YG, Zhang JB, He JZ. 2008. Abundance and composition of ammoniaoxidizing bacteria and ammonia-oxidizing archaea communities of an alkaline sandy loam. Environmental microbiology 10:1601-11.

28. Shen LD, Huang Q, He ZF, Lian X, Liu S, et al. 2014. Vertical distribution of nitrite-dependent anaerobic methane-oxidising bacteria in natural freshwater wetland soils. Applied microbiology and biotechnology.

29. Stein, L., Klotz, M., 2016. The nittogen cycle. Current Biology 3, 94-98.

30. Stewart FJ,Ulloa O, DeLong EF (2012) Microbial metatranscriptomics ina permanent marine oxygen minimum zone. Environ Microbiol 14:23-40.

31. Verhamme DT, Prosser JI, Nicol GW (2011) Ammonia concentrationdetermines differential growth of ammonia-oxidising archaea andbacteria in soil microcosms. ISME J 5:1067-1071. 
32. Wang C, Tang SY, He XJ, Ji GD. 2020. The abundance and community structure of active ammoniaoxidizingarchaea and ammonia-oxidizing bacteria shape their activities andcontributions in coastal wetlands. Water Research 171: 115464.

33. Yu SL, Yao P, Liu JW, Zhao B, Zhang GL, Zhao MX, Yu ZG, Zhang XH (2016) Diversity, abundance, and niche differentiationof ammonia-oxidizing prokaryotes in mud deposits of the easternChina marginal seas. Front Microbiol 7(137):137.

34. Zhang, Q., Li, Y., He, Y., Brookes, P.C., Xu, J., 2019b. Elevated temperature increased nitrification activity by stimulating AOB growth and activity in an acidic paddy soil. Plant and Soil 445, 71-83.

35. ZhengYL, Hou LJ, Liu M, LuM, Zhao H, Yin GY, Zhou JL (2013) Diversity, abundance, and activity of ammonia-oxidizing bacteria and archaea in Chongming eastern intertidal sediments. Appl Microbiol Biotechnol 97 (18):8351-8363.

36. Zheng YL, Hou LJ, Newell S, Liu M, Zhou JL, Zhao H, You LL,Cheng XL (2014) Community dynamics and activity of ammoniaoxidizingprokaryotes in intertidal sediments of theYangtze estuary.Appl Environ Microbiol 80(1):408-419.

\section{Figures}




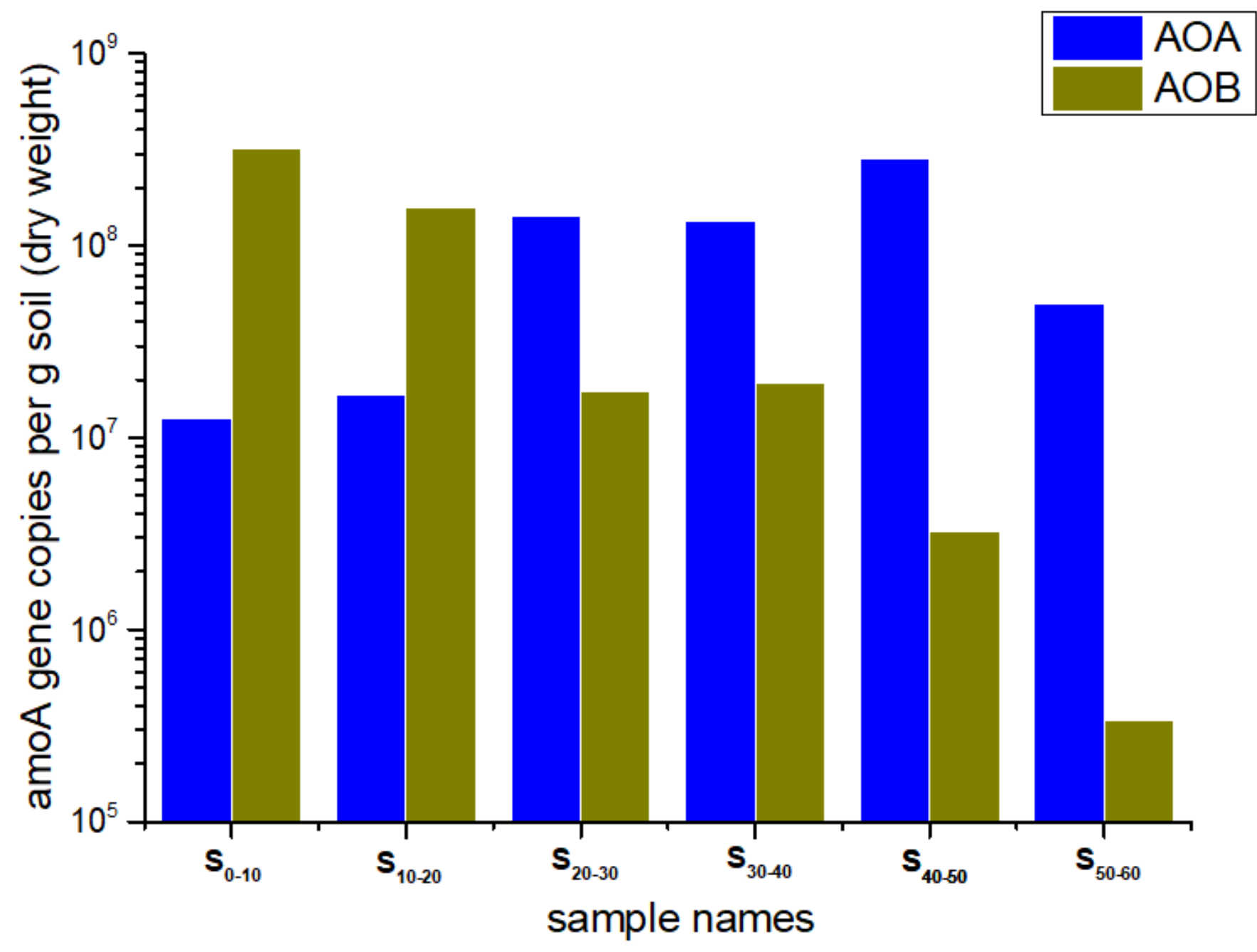

Figure 1

Quantitative analysis of $A O A$ and $A O B$ in the six sediment samples 


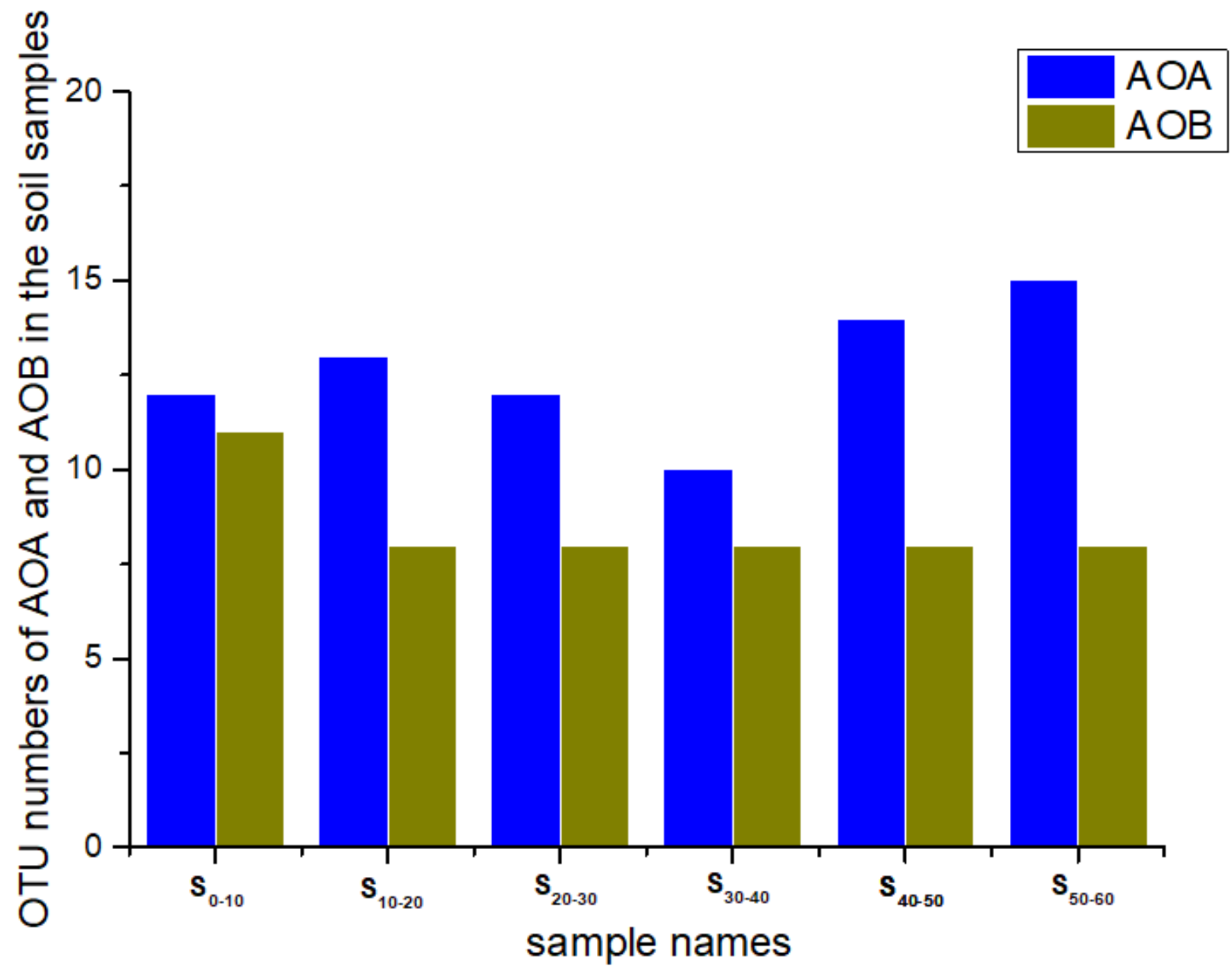

Figure 2

The OTU numbers of $A O A$ and $A O B$ in the six sediment samples 


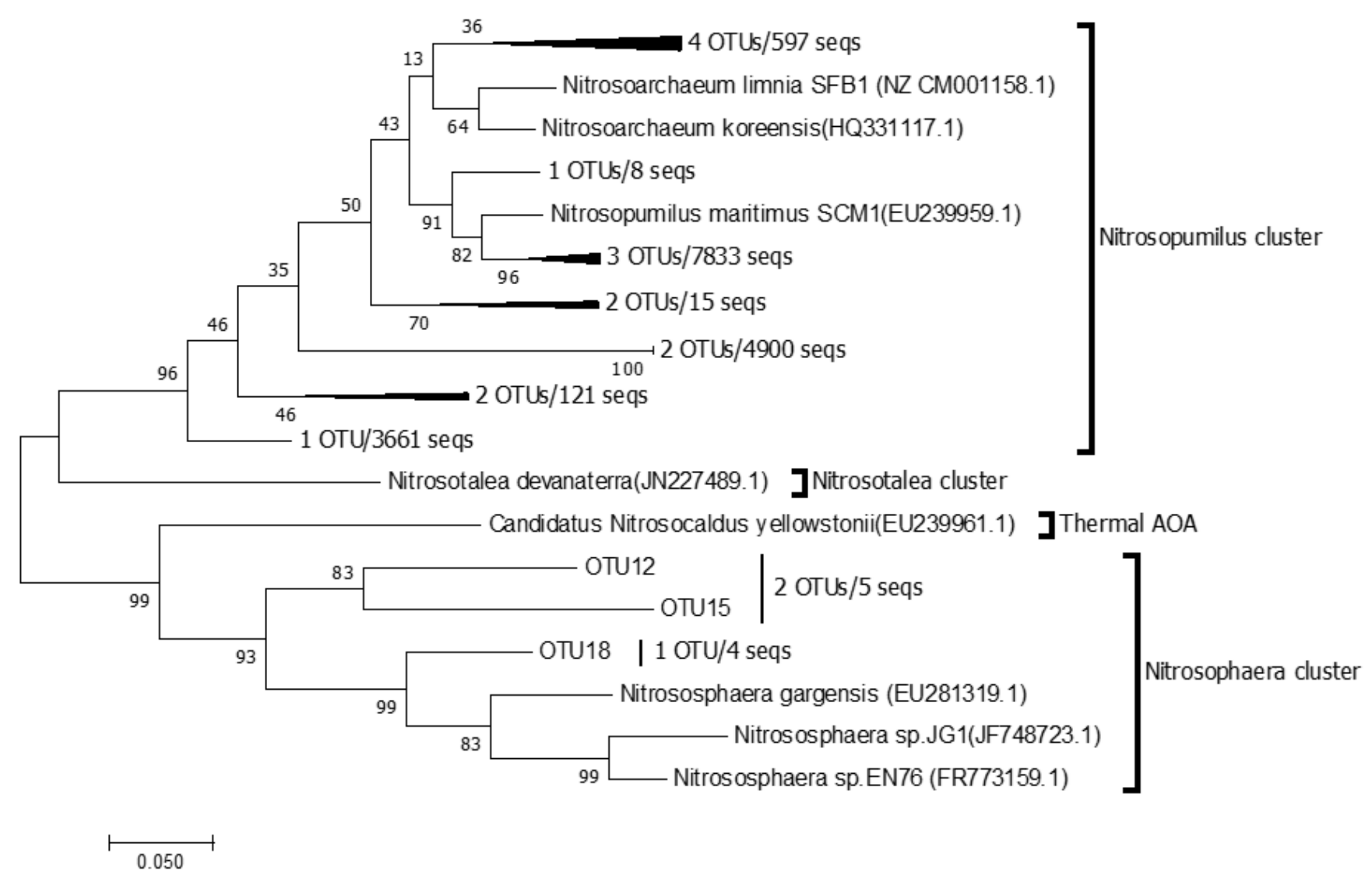

\section{Figure 3}

Maximum-Likehood phylogenetic tree showing the phylogenetic affiliations of the AOA sequences recovered from the sediment samples. The numbers at the nodes are percentages that indicate thelevels of bootstrap support from 2000 replicates. The scale barrepresents 0.05 nucleic acid substitutions per nucleotide position.

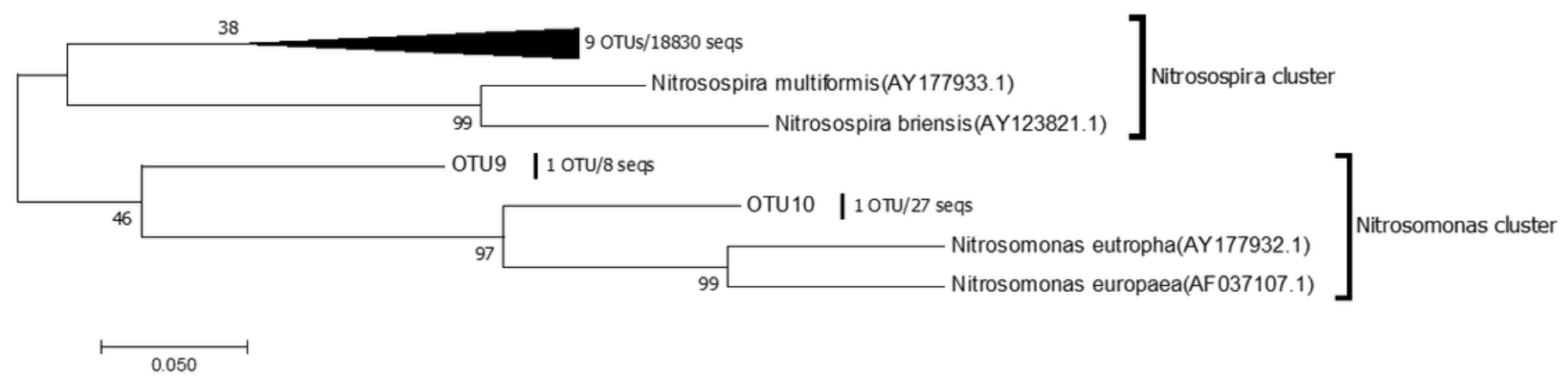

\section{Figure 4}

Maximum-Likehood phylogenetic tree showing the phylogenetic affiliations of the AOB sequences recovered from the sediment samples. The numbers at the nodes are percentages that indicate thelevels 
of bootstrap support from 2000 replicates. The scale barrepresents 0.05 nucleic acid substitutions per nucleotide position.

\section{Supplementary Files}

This is a list of supplementary files associated with this preprint. Click to download.

- SupplementalMaterial.docx 